\title{
Combined IR and XPS characterization of organic refractory residues obtained by ion irradiation of simple icy mixtures
}

\author{
M. Accolla ${ }^{1}$, G. Pellegrino ${ }^{2}$, G. A. Baratta ${ }^{1}$, G. G. Condorelli ${ }^{3}$, G. Fedoseev ${ }^{1}$, C. Scirè ${ }^{1}$, \\ M. E. Palumbo ${ }^{1}$, and G. Strazzulla ${ }^{1}$ \\ 1 INAF-Osservatorio Astrofisico di Catania, Via Santa Sofia 78, 95123 Catania, Italy \\ e-mail: mario.accolla@oact.inaf.it \\ 2 CNR - IMM,Via Santa Sofia 64, 95123 Catania, Italy \\ 3 Dipartimento di Scienze Chimiche, Università degli Studi di Catania, Viale Andrea Doria 6, 95125 Catania, Italy
}

Received 9 August 2018 / Accepted 7 October 2018

\begin{abstract}
Context. Multi-year laboratory experiments have demonstrated that frozen icy mixtures containing simple organic and inorganic molecules (such as $\mathrm{H}_{2} \mathrm{O}, \mathrm{N}_{2}, \mathrm{CH}_{4}, \mathrm{CO}, \mathrm{CO}_{2}, \mathrm{C}_{2} \mathrm{H}_{6}$, etc.), if exposed to a flux of energetic ions or UV photons, give rise to new more complex molecules at low temperatures $(10-50 \mathrm{~K})$. A fraction of the new synthesized molecules is volatile while the remaining fraction is refractory and therefore it is preserved after the warm-up of the substrate to room temperature. Moreover, a part of the refractory material is formed during the annealing to room temperature, when molecules and radicals into the processed ice become mobile and react to form non-volatile molecules. By means of similar mechanisms, complex organic materials may be formed on the icy surfaces of some objects in the outer solar system, such as trans-Neptunian objects, comets and some satellites of the giant planets: in fact the interaction with solar wind and solar flares ions, solar photons and galactic cosmic rays could produce more refractory materials, analogous to those produced in the laboratory. In some cases, the materials thus synthesized may contain functional groups considered relevant to the pre-biotic chemistry in the hypothesis that interplanetary dust particles, comets and meteoroids contributed to seed the early Earth with the building blocks of life.

Aims. The aim of this work is to investigate the chemical similarities and differences between some organic residues left over after ion bombardment $\left(200 \mathrm{keV} \mathrm{H}^{+}\right)$of different ice mixtures followed by subsequent warm up under vacuum to room temperature.

Methods. Seven organic residues have been prepared in our laboratory following a procedure involving the proton irradiation of seven different icy mixtures and their warm-up to room temperature. All the organic samples were characterized by FTIR spectroscopy with measurements performed in situ, in the ultra-high vacuum condition preventing any sample degradation. Three of them were selected to be characterized by XPS spectroscopy as well.

Results. Among the organic residues presented in this paper, only those containing nitrogen and carbon exhibit the multi-component band centred at $2200 \mathrm{~cm}^{-1}$. This multi-component band presents interest from the astrobiological point of view due to its attribution to nitriles $(-\mathrm{C} \equiv \mathrm{N})$ and isonitriles $(-\mathrm{N} \equiv \mathrm{C})$. Our results demonstrate that this band is present in the IR spectra of organic nitrogen residues regardless the use of oxygen-bearing species in the icy mixture. This finding is of interest since the $2200 \mathrm{~cm}^{-1}$ band has been observed in some extraterrestrial samples (micro-meteorites) collected in the Antarctica.
\end{abstract}

Key words. astrochemistry - astrobiology - methods: laboratory: solid state

\section{Introduction}

Since the 1970s, several laboratories world-wide investigated the formation of radicals and new species after energetic processing (ion and electron bombardment and/or UV photolysis) of simple organic and inorganic frozen molecules such as $\mathrm{H}_{2} \mathrm{O}, \mathrm{N}_{2}, \mathrm{CH}_{4}, \mathrm{CO}, \mathrm{CO}_{2}, \mathrm{C}_{2} \mathrm{H}_{6}$, etc. (e.g. Greenberg et al. 1972; d'Hendecourt et al. 1986; Moore et al. 2001; Strazzulla et al. 2001; Öberg et al. 2009; Nuevo et al. 2010; Materese et al. 2015; Rothard et al. 2017). It is well known that ion and UV-photon irradiation induce similar chemical alteration on the ices from a qualitative point of view, whereas differences can be observed in the yields of destruction or production of species (see Islam et al. 2014; Muñoz Caro et al. 2014, and references therein). Infrared spectroscopy of frozen samples after the energetic processing shows the appearance of new bands indicating the synthesis of new molecules. Raman spectroscopy of some ion irradiated ices shows the formation of hydrogenated amorphous carbon if the unprocessed icy sample contains simple hydrocarbons (e.g. Ferini et al. 2004; Palumbo et al. 2004). The organic material synthesized in simple icy mixtures containing $\mathrm{H}-, \mathrm{C}-, \mathrm{N}-$, and O-bearing molecules is believed to be a good analogue of that expected in some astrophysical objects, such as transNeptunian objects (TNOs), cold planetary satellites, comets in the Oort cloud, etc. (e.g. Brunetto et al. 2006; Materese et al. 2014; Urso et al. 2017). The organic material left over after the energetic processing of a simple icy mixture and the following warm-up is commonly called organic residue and remains, at room temperature after the sublimation of the most volatile species, as a yellow-brownish film on the substrate where the icy sample was processed. The literature concerning the study of non-volatiles residues is wide and many references are reported in the following sections. Refractory residues have been usually characterized by infrared spectroscopy that is a non-destructive (but low sensitivity) analytical technique. In recent decades, refractory residues have been studied by high sensitivity analytical methods, such as gas chromatography coupled with mass spectroscopy (GC-MS) and X-ray absorption near-edge 
structure (XANES). These techniques allow the detection of complex molecules in the organic residues even if they are present in low abundance. For instance, a multi-diagnostic approach (IR, GC-MS and XANES) has been used to study the organic residues formed after UV photolysis (Materese et al. 2014) and after electron bombardment (Materese et al. 2015) of $\mathrm{N}_{2}: \mathrm{CH}_{4}: \mathrm{CO}$ icy mixtures in relative proportion $(100: 1: 1)$. In both cases the authors reveal the presence of glycolic acid $\left(\mathrm{C}_{2} \mathrm{H}_{4} \mathrm{O}_{3}\right)$, 3-hydroxypropionic acid $\left(\mathrm{C}_{3} \mathrm{H}_{6} \mathrm{O}_{3}\right)$ and urea $\left(\mathrm{CH}_{4} \mathrm{~N}_{2} \mathrm{O}\right)$, while lactic acid $\left(\mathrm{C}_{3} \mathrm{H}_{6} \mathrm{O}_{3}\right)$, oxalic acid $\left(\mathrm{C}_{2} \mathrm{H}_{2} \mathrm{O}_{4}\right)$, 2-hydroxybutyric acid $\left(\mathrm{C}_{4} \mathrm{H}_{8} \mathrm{O}_{3}\right)$ and glyceric acid $\left(\mathrm{C}_{3} \mathrm{H}_{6} \mathrm{O}_{4}\right)$ are detected only in the residue left over after UV irradiation of the sample. Muñoz Caro et al. (2002) and Nuevo et al. (2010) detect some amino acids analysing by GC-MS some refractory residues obtained from photoprocessed astrophysical ice analogue mixtures. Other authors (e.g. Kaiser \& Balucani 2001; Hudson et al. 2008; Fedoseev et al. 2015) propose different pathways to form amino acids starting from hydrolysis of nitrogen-rich organic matter formed upon energetic and thermal processing of icy mixtures. The detection of complex molecules in organic residues is considered relevant from the astrobiological point of view in the hypothesis that the delivery of extraterrestrial organic compounds by means of interplanetary dust particles (IDPs), comets and meteorites may have contributed to seed the early Earth with the building blocks of life few billion of years ago (see Cobb et al. 2015; Altwegg et al. 2016, and references therein).

In this paper we study seven different organic residues, each obtained after proton irradiation of seven icy mixtures with different amount of carbon, nitrogen, oxygen and hydrogen bearing species. The seven solid samples are characterized by means of in situ transmittance infrared spectroscopy. Three of these samples are selected to be studied also by X-ray photoelectron spectroscopy (XPS) for more in-depth elemental analysis. These two analytical techniques allow us to stress analogies and differences between the seven samples.

The paper is organized as follows: Sect. 2 describes both the procedure to prepare the seven refractory organic samples and the experimental set-up used to develop and characterize them. In Sect. 3 the experimental results are presented, focusing on the differences and similarities among the IR spectra of the seven samples. Moreover, for three of these samples, an elemental analysis, performed by means of XPS spectroscopy, is displayed and discussed. In Sect. 4 we discuss the experimental results in view of their astrophysical implications in Sect. 5.

\section{Experimental procedure}

\subsection{Sample preparation and IR spectroscopy}

The preparation and the IR characterization of the organic samples are performed in the Laboratory for Experimental Astrophysics (LASp) at INAF - Osservatorio Astrofisico di Catania (Italy). The laboratory is equipped with an experimental setup thought to study the interaction between energetic ions or photons with icy mixtures, analogous to those observed in several astrophysical scenarios. A schematic drawing of the equipment is shown in Fig. 1. The apparatus consists of a stainless steel ultrahigh-vacuum (UHV) chamber, operating at a pressure of around $10^{-9}$ mbar, directly connected to a $200 \mathrm{kV}$ ion implanter (Danfysik 1080-200) able to generate and accelerate an ion beam with energy up to $200 \mathrm{keV}$ per single ionization and finally to aim it at a substrate (acting as sample holder) inside the UHV chamber. The substrate (usually an infrared-transparent window

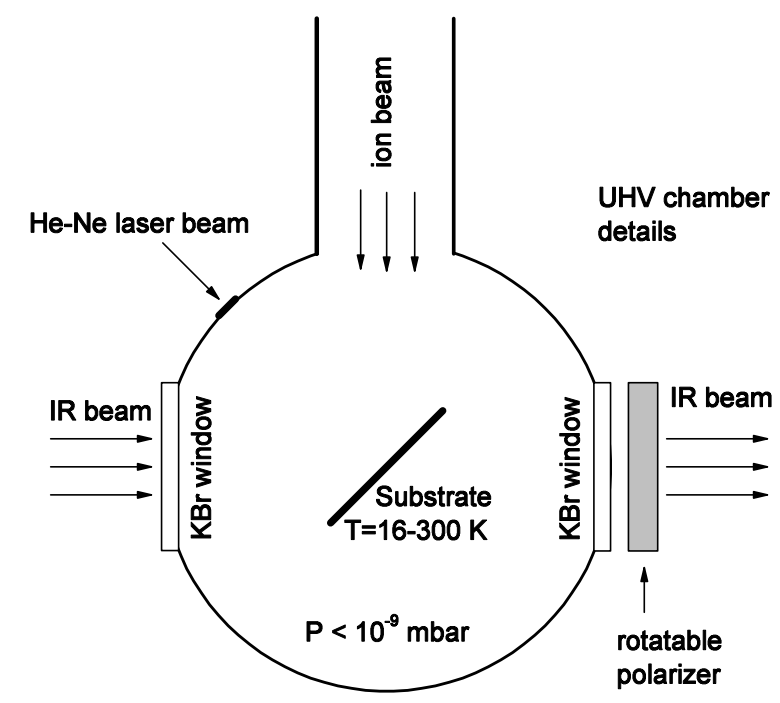

Fig. 1. Schematic view of the experimental set-up in the Laboratory for Experimental Astrophysics (LASp) at INAF - Osservatorio Astrofisico di Catania (Italy).

such as $\mathrm{KBr}$ or silicon) is placed in thermal contact with a cold finger of a closed-cycle He cryostat, whose temperature can be varied between 16 and $300 \mathrm{~K}$. The substrate forms an angle of $45^{\circ}$ both with the ion beam and with the infrared beam coming from the IR source of a spectrometer. A hole in the cold finger allows the infrared beam to be transmitted through the infraredtransparent substrate so that transmittance IR spectra can be easily taken in situ, even during ion bombardment, without tilting the sample.

A separate mixing chamber is used to prepare the gaseous mixture and to admit it into the UHV chamber by means of a needle valve. When the gaseous mixture is admitted into the main chamber, it freezes onto the substrate previously cooled forming the icy sample. During the ice growing, the thickness is monitored by checking the interference fringes produced by a $\mathrm{He}-\mathrm{Ne}$ laser beam reflected at near normal incidence both by the vacuum-film and film-substrate interfaces. Laser light enters and leaves the chamber through a fused silica window whose surface is parallel to the substrate inside the chamber (see Fig. 1). Further details about the method for the thickness measurements are reported in Urso et al. (2016).

In situ infrared transmission spectra are taken at oblique incidence $\left(45^{\circ}\right)$ by a Fourier transform infrared (FTIR) spectrometer (Bruker-Vertex 70): on the wall of the UHV chamber, two $\mathrm{KBr}$ windows facing each other allows the infrared light coming from the spectrometer to enter and exit. On its path inside the chamber, the infrared light crosses the sample and its transparent holder. A rotatable polarizer is placed along the path of the IR beam outside the UHV chamber and allows us to take spectra both with the electric vector parallel ( $p$-polarized) and perpendicular ( $s$-polarized) to the plane of incidence.

The seven organic samples analysed in this work are listed in Table 1 and are produced by $200 \mathrm{keV}$ proton irradiation of different frozen gases at $17 \mathrm{~K}$, following a well-established laboratory procedure described hereafter. The elemental composition of the organic residues is strictly linked to the icy mixtures from which they are originated. The experimental procedure to prepare the seven organic residues is identical for all the samples in Table 1 and consists of the following six steps: (1) the chosen gaseous mixture is prepared into a mixing chamber formerly evacuated at a pressure lower than $10^{-6}$ mbar; (2) by means of 
Table 1. The seven samples analysed in this paper.

\begin{tabular}{clccccccccc}
\hline \hline No. & $\begin{array}{l}\text { Icy mixture } \\
\text { (at } 17 \mathrm{~K})\end{array}$ & $\begin{array}{c}\text { Thickness } \\
(\mu \mathrm{m})\end{array}$ & $\begin{array}{c}\mathrm{N} \\
\%\end{array}$ & $\begin{array}{l}\mathrm{C} \\
\%\end{array}$ & $\begin{array}{c}\mathrm{O} \\
\%\end{array}$ & $\begin{array}{c}\mathrm{H} \\
\%\end{array}$ & $\begin{array}{c}\mathrm{Ar} \\
\%\end{array}$ & Ion projectile & $\begin{array}{c}\text { Dose } \\
(\mathrm{eV} / 16 \mathrm{u})\end{array}$ & $\begin{array}{c}\text { Organic residue } \\
(\text { at } 290 \mathrm{~K})\end{array}$ \\
\hline 1 & $\mathrm{~N}_{2}: \mathrm{CH}_{4}(1: 1)$ & 2.2 & 29 & 14 & - & 57 & - & $200 \mathrm{keV} \mathrm{H}^{+}$ & 126 & Res \#1 \\
2 & $\mathrm{~N}_{2}: \mathrm{CH}_{4}: \mathrm{CO}(1: 1: 1)$ & 1.3 & 22 & 22 & 11 & 45 & - & $200 \mathrm{keV} \mathrm{H}^{+}$ & 106 & Res \#2 \\
3 & $\mathrm{~N}_{2}: \mathrm{CH}_{4}: \mathrm{H}_{2} \mathrm{O}(1: 1: 1)$ & 1.3 & 20 & 10 & 10 & 60 & - & $200 \mathrm{keV} \mathrm{H}^{+}$ & 122 & Res \#3 \\
4 & $\mathrm{~N}_{2}: \mathrm{C}_{8} \mathrm{H}_{18}(1: 1)$ & 2.8 & 7 & 29 & - & 64 & - & $200 \mathrm{keV} \mathrm{H}^{+}$ & 16 & Res \#4 \\
5 & $\mathrm{~N}_{2}: \mathrm{C}_{8} \mathrm{H}_{18}(9: 1)$ & 2.8 & 41 & 18 & - & 41 & - & $200 \mathrm{keV} \mathrm{H}^{+}$ & 16 & Res \#5 \\
6 & $\mathrm{Ar}: \mathrm{C}_{8} \mathrm{H}_{18}(10: 1)$ & 2.8 & - & 22 & - & 50 & 28 & $200 \mathrm{keV} \mathrm{H}^{+}$ & 16 & Res \#6 \\
7 & $\mathrm{CO}: \mathrm{CH}_{4}(1: 1)$ & 2.2 & - & 29 & 14 & 57 & - & $200 \mathrm{keV} \mathrm{H}^{+}$ & 120 & Res \#7 \\
\hline
\end{tabular}

a needle valve, the prepared gaseous mixture is admitted into the main chamber where it freezes on a $\mathrm{KBr}$ substrate at $17 \mathrm{~K}$; (3) the growth of the ice on the substrate is continuously monitored with the laser interference fringe measurement system; (4) after deposition, the infrared spectrum of the initial sample is taken; (5) then the icy mixture is bombarded by $200 \mathrm{keV} \mathrm{H}^{+}$ions at various irradiation steps as long as the total energy released by impinging ions reaches the required value: after each irradiation step IR spectra are taken; (6) finally, the irradiated icy mixture is gently warmed up to room temperature under vacuum condition overnight: a brownish material, the refractory organic residue, is present on the surface of the $\mathrm{KBr}$ substrate after all the volatile species embedded in the irradiated ice have sublimated.

For each sample discussed in this paper, we collected the IR spectra before, during and after ion irradiation, during annealing of the substrate to follow the sublimation of the volatile components and finally at room temperature. All the IR spectra shown in this paper are taken in situ, with the electric vector parallel ( $p$-polarized) to the plane of incidence, resolution of $1 \mathrm{~cm}^{-1}$ and sampling of $0.25 \mathrm{~cm}^{-1}$. The thicknesses reported in the third column of Table 1 for each icy sample are measured before ion bombardment. Each of these frozen samples has a thickness lower than the penetration depth of the incoming ions as theoretically predicted by the SRIM code (Ziegler et al. 2008). The thicknesses of the corresponding refractory residues left over after all the volatile species in the irradiated frozen mixtures have sublimated are not directly measurable. According to the measurements presented by Baratta et al. (2015) using similar experimental conditions, we can state that the thickness of each residue typically decreases by $85-90 \%$ with respect to that of the un-irradiated ice. In this paper the energy deposited by the incoming ions to the seven samples (dose) is calculated by multiplying the ion fluence by the stopping power (i.e. the amount of energy deposited per unit path length; $\mathrm{eV} \mathrm{cm}^{2} \mathrm{~mol}^{-1}$ ) given by SRIM code (Ziegler et al. 2008). For each sample, the obtained value is reported in the penultimate column of Table 1: dose is given in $\mathrm{eV} / 16 \mathrm{u}$, which is a convenient way to characterize chemical changes and to enable a direct comparison with other experiments using various samples (Strazzulla \& Johnson 1991). A more detailed description of the equipment available in the LASp can be found elsewhere (e.g. Strazzulla et al. 2001; Palumbo et al. 2004; Islam et al. 2014; Baratta et al. 2015).

\subsection{XPS analysis}

X-ray Photoelectron Spectroscopy (XPS) measurements are performed at the Dipartimento di Scienze Chimiche, Università di Catania, using a PHI ESCA/SAM 5600 Multi-technique spectrometer equipped with a Mg standard X-ray source. The pressure in the chamber is $\sim 10^{-9}$ mbar. The analyses are carried out at $45^{\circ}$ photoelectron takeoff angle relative to the sample surface with an acceptance angle of $\pm 7^{\circ}$. The binding energy (BE) scale is calibrated by centring the $\mathrm{C} 1 \mathrm{~s}$ signal of the hydrocarbon and adventitious carbon component at $285.0 \mathrm{eV}$.

Measurements of XPS are performed ex situ. Hence, organic samples are extracted from the vacuum chamber in the Laboratory for Experimental Astrophysics, stored in laboratory for a time frame of some hours and then placed into the XPS vacuum chamber.

\section{Results}

\subsection{In situ FTIR characterization}

Figure 2 shows the in situ transmission infrared spectra in optical depth scale of the seven organic residues in the spectral region $4000-1000 \mathrm{~cm}^{-1}$. Each spectrum has been collected at room temperature the day after the ion irradiation of the corresponding icy mixture. In situ measurements performed in the ultra-high vacuum condition prevent any contamination of the residues.

Table 1 shows which elements are present in each icy sample and their relative abundances (i.e. number of atoms) before ion bombardment. In the following subsections, to facilitate the discussion, we have divided the IR spectra into three different spectral regions: (1) $3900-2300 \mathrm{~cm}^{-1}$; (2) $2300-2000 \mathrm{~cm}^{-1}$; (3) $1900-1000 \mathrm{~cm}^{-1}$.

\subsubsection{Spectral region: $3900-2300 \mathrm{~cm}^{-1}$}

Keeping in mind the elemental composition of the icy mixtures from which the seven organic residues are prepared, the possible functional groups falling in the spectral region $3900-2300 \mathrm{~cm}^{-1}$ are: $-\mathrm{NH}-,-\mathrm{NH}_{2},-\mathrm{OH},-\mathrm{CH}_{3}$, and $-\mathrm{CH}_{2}-$.

We now consider Fig. 3: Res \#2 and Res \#3 exhibit a broad structured band between 3500 and $2500 \mathrm{~cm}^{-1}$ probably due to $-\mathrm{NH}_{2}$ and $-\mathrm{NH}-$ (primary and secondary amine functional groups respectively) and $-\mathrm{OH}$ functional groups, with an overlapping of $\mathrm{C}-\mathrm{H}$ stretching features observed on top of this broad band (Baratta et al. 2015; Materese et al. 2015). Res \#1 and Res \#5 display similar features due to the amines and an overlapping of $\mathrm{C}-\mathrm{H}$ (Imanaka et al. 2004). In this case we can exclude the contribution of $-\mathrm{OH}$ functional groups because Sample \#1 and Sample \#5 do not contain any oxygen-bearing species; furthermore the measurements are performed in situ in the ultra-high vacuum condition and thus we can exclude any contamination into the residue. 


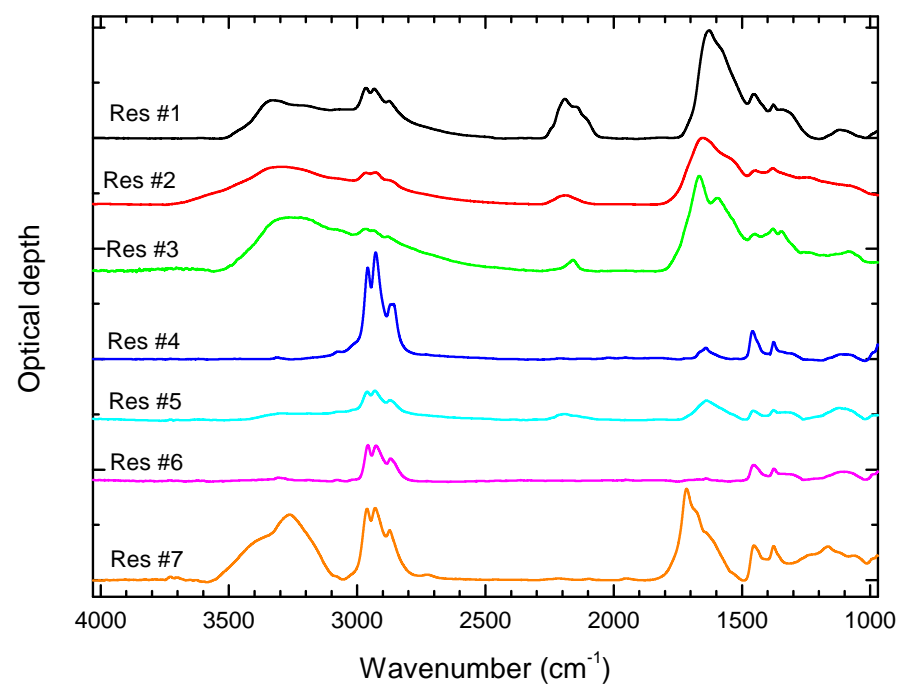

Fig. 2. Infrared spectra of the seven organic residues analysed in this work. Spectra are taken in situ at room temperature and are vertically shifted for clarity.

Looking at Fig. 3, we notice that the seven residues exhibit three features close to each other (at 2960, 2927 and $2870 \mathrm{~cm}^{-1}$ ) peculiar of the aliphatic $\mathrm{C}-\mathrm{H}$ bonds. In particular, the $2870 \mathrm{~cm}^{-1}$ and $2960 \mathrm{~cm}^{-1}$ bands are attributed respectively to $-\mathrm{CH}_{3} \mathrm{sym}-$ metric and asymmetric stretching, while the $2927 \mathrm{~cm}^{-1}$ band is attributed to $-\mathrm{CH}_{2}$ symmetric stretching (Gautier et al. 2012; Greenberg et al. 1995). We can also note that the intensity of these three features varies according to the residue taken into consideration, mostly depending on the elemental abundances of the icy mixture before ion irradiation. For instance, Sample \#4 and Sample \#5 are both composed of nitrogen $\left(\mathrm{N}_{2}\right)$ and octane $\left(\mathrm{C}_{8} \mathrm{H}_{18}\right)$ but with different initial ratio (see Table 1): in Sample \#4 $\mathrm{N} / \mathrm{C}$ is 0.25 while in Sample \#5 N/C is greater than two. As Sample \#4 and Sample \#5 had identical thickness and suffered the same dose, we can directly compare the IR spectra of the two corresponding residues (namely Res \#4 and Res \#5): the lower availability of nitrogen in Sample \#4 promotes the formation of the aliphatic chains and inhibits the formation of nitriles. Hence, Res $\# 4$ exhibits $\mathrm{CH}$ stretching mode features more intense and $\mathrm{CN}$ features less intense than those observed in Res \#5 (see more details in Sect. 3.1.2). The organic residue Res \#7, originated by ion irradiation of the icy mixture containing carbon monoxide $(\mathrm{CO})$ and methane $\left(\mathrm{CH}_{4}\right)$, exhibits a multi-component band between 3600 and $3060 \mathrm{~cm}^{-1}$ mainly due to $\mathrm{O}-\mathrm{H}$ bonds.

\subsubsection{Spectral region: $2300-2000 \mathrm{~cm}^{-1}$}

As discussed elsewhere (e.g. Palumbo et al. 2000a,b), the spectral region $2300-2000 \mathrm{~cm}^{-1}$ draws special interest from astrobiologists because the triple $\mathrm{CN}$ bonds of nitriles that are considered relevant to pre-biotic chemistry, fall in this region. Looking at Fig. 4, we noticed that the residues originated by icy mixtures free of nitrogen (Res \#6 and Res \#7) exhibit no important features in this spectral region. The IR spectrum of Res \#4 shows very weak features in this spectral region: although the icy Sample \#4 before ion bombardment contains nitrogen, the great availability of carbon $(\mathrm{N} / \mathrm{C}=0.25)$ promotes the formation of $\mathrm{C}-\mathrm{H}$ aliphatic bonds to the detriment of $\mathrm{CN}$ bonds.

Vice versa, Res \#1, Res \#2, Res \#3 and Res \#5 exhibit a multi-picked band centred at about $2200 \mathrm{~cm}^{-1}$. The vertical

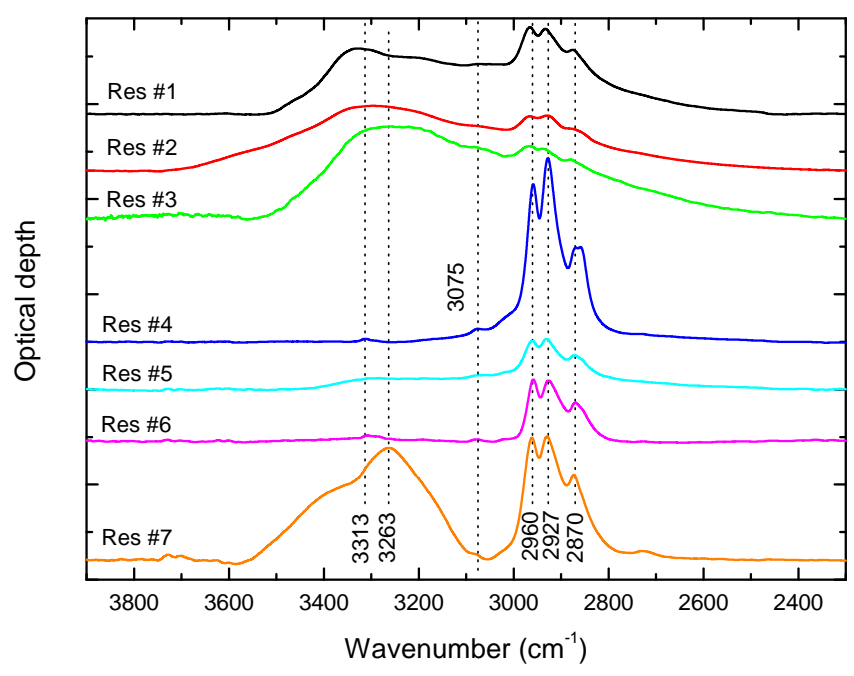

Fig. 3. Infrared spectra (3900-2300 $\mathrm{cm}^{-1}$ region) of the seven organic residues analysed in this work. Spectra are collected in situ at room temperature.

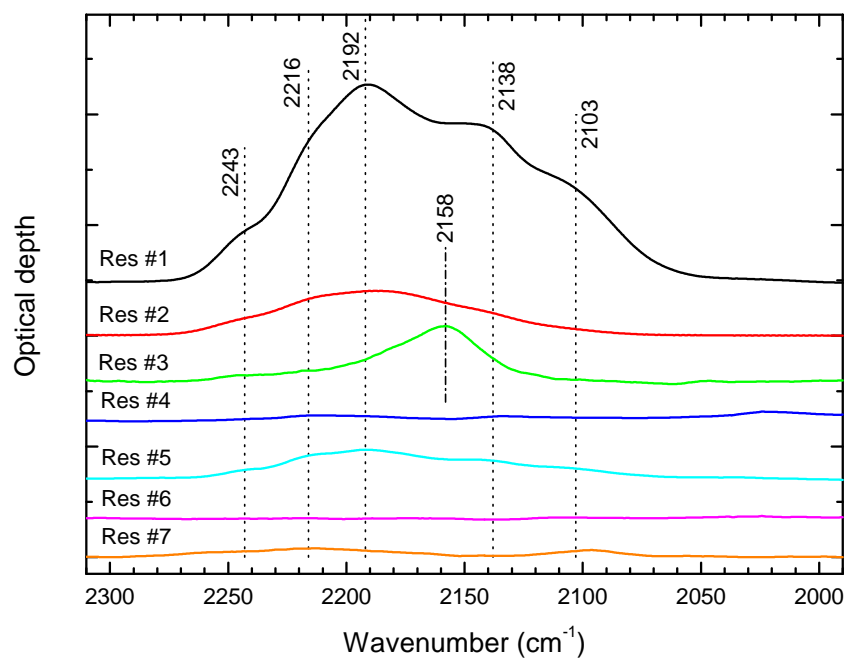

Fig. 4. Infrared spectra $\left(2300-2000 \mathrm{~cm}^{-1}\right.$ region) of the seven organic residues analysed in this work. Spectra are collected in situ at room temperature.

dotted lines in Fig. 4 stress five components clearly recognizable at least for Res \#1 Res \#2 and Res \#5: two of these components $\left(2243\right.$ and $\left.2216 \mathrm{~cm}^{-1}\right)$ are commonly assigned to nitriles $(-\mathrm{C} \equiv \mathrm{N})$ while the remaining three $\left(2192,2138\right.$ and $\left.2103 \mathrm{~cm}^{-1}\right)$ to isonitriles $(-\mathrm{N} \equiv \mathrm{C})$ (Mutsukura \& Akita 1999; Imanaka et al. 2004).

The dot-dash vertical line in Fig. 4 highlights that Res \#3 displays a band whose main feature is peaked at $2158 \mathrm{~cm}^{-1}$, namely a different frequency with respect to those observed for Res \#1, Res \#2 and Res \#5. Moreover, this band does not display the same components observed for the other residues. We can suppose that the presence of $\mathrm{H}_{2} \mathrm{O}$ as component of the icy mixture (Sample \#3) could affect the chemical rearrangements into the ice during both ion irradiation at $17 \mathrm{~K}$ and the subsequent annealing to room temperature. In order to investigate the nature of the features detected in residues Res \#1, Res \#2, Res \#3, and Res \#5 at room temperature ( $T=290 \mathrm{~K}$ ), it is useful to pay attention to the evolution of the IR features in the same spectral region starting from the spectra of the corresponding icy mixtures just after ion irradiation at $17 \mathrm{~K}$, during the following warm-up (e.g. 
M. Accolla et al.: IR and XPS characterization of organic refractory residues

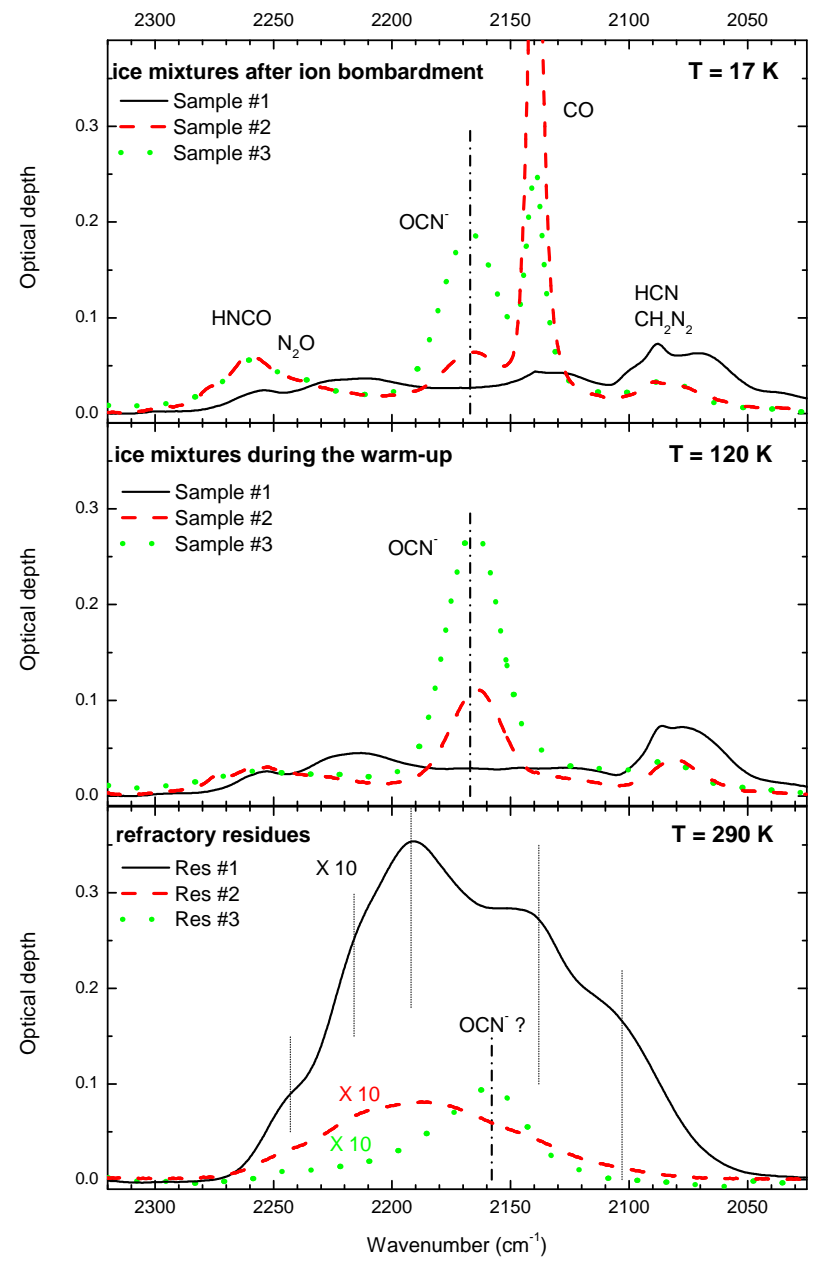

Fig. 5. Spectra in the $2320-2025 \mathrm{~cm}^{-1}$ region, evolving with the temperature for three icy mixtures after ion exposure. Sample \#1 $\left(\mathrm{N}_{2}: \mathrm{CH}_{4}+200 \mathrm{keV} \mathrm{H}{ }^{+}\right)$, Sample \#2 $\left(\mathrm{N}_{2}: \mathrm{CH}_{4}: \mathrm{CO}+200 \mathrm{keV} \mathrm{H}{ }^{+}\right)$, and Sample \#3 $\left(\mathrm{N}_{2}: \mathrm{CH}_{4}: \mathrm{H}_{2} \mathrm{O}+200 \mathrm{keV} \mathrm{H}{ }^{+}\right)$. Top panel: IR spectra of the three samples at $17 \mathrm{~K}$, just after ion irradiation. Central panel shows the IR spectra of the three samples at $120 \mathrm{~K}$, during warm-up. Bottom panel: IR spectra of the three corresponding refractory organic residues at room temperature, magnified 10 times for the sake of clarity.

at $120 \mathrm{~K}$ ) and finally at room temperature. To do that, we consider an icy mixture containing $\mathrm{N}, \mathrm{C}$, and $\mathrm{H}$ (Sample \#1), and two different icy mixtures containing N, C, H, and O (Sample \#2 and Sample \#3). Top panel of Fig. 5 shows the IR spectra of the icy samples \#1, \#2, and \#3 at the end of the ion bombardment at $17 \mathrm{~K}$ : Sample \#2 and Sample \#3 exhibit a feature peaked at $2167 \mathrm{~cm}^{-1}$. The nature of this band, also detected in some astrophysical sources at low temperature (e.g. Pendleton et al. 1999; Pontoppidan et al. 2003; van Broekhuizen et al. 2005), has been largely discussed in the past. Now it is commonly attributed to the $\mathrm{OCN}^{-}$ion (Hudson et al. 2001; Novozamsky et al. 2001; Bennett et al. 2010). As shown in the central panel of Fig. 5 , the $\mathrm{OCN}^{-}$band observed in the two samples is still detected at $120 \mathrm{~K}$ during the warm-up, with a greater strength and a slightly different peak position. The absence of this band both at $17 \mathrm{~K}$ and at $120 \mathrm{~K}$ in the spectrum of Sample \#1 is due to the lack of oxygen-bearing species in the initial icy mixture. Nevertheless, at room temperature, the refractory residues Res \#1 and Res \#2 display a $2200 \mathrm{~cm}^{-1}$ multi-peaked band having shape and features very similar to each other (see the bottom panel of Fig. 5) and thus due to the same functional groups. This indicates that

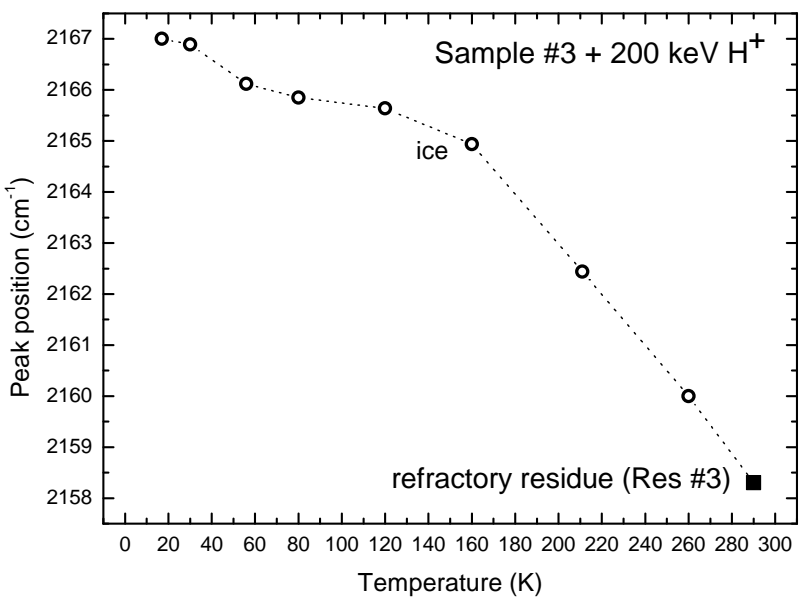

Fig. 6. Evolution of the position of the band assigned to $\mathrm{OCN}^{-}$during the slow warm-up of the irradiated Sample \#3 from $17 \mathrm{~K}$ to room temperature.

oxygen-bearing species (such as $\mathrm{OCN}^{-}$) do not contribute to the $2200 \mathrm{~cm}^{-1}$ band observed in the organic residues at room temperature.

As highlighted in the bottom panel of Fig. 5, the IR spectrum of Res \#3 at room temperature exhibits a band peaked at $2158 \mathrm{~cm}^{-1}$, whose attribution is not clear. The position could suggest that the band may be due to $\mathrm{OCN}^{-}$trapped in the organic residue at room temperature. In fact starting from the position of the $\mathrm{OCN}^{-}$band in the irradiated Sample \#3 at $17 \mathrm{~K}\left(2167 \mathrm{~cm}^{-1}\right)$, we monitored the peak position of this band at different temperatures during the whole warm-up of the icy sample and we recorded a gradual shift towards lower wavenumbers as the sample temperature increases, reaching $2160 \mathrm{~cm}^{-1}$ at $260 \mathrm{~K}$ (see Fig. 6). Then the frequency of the peak recorded for the refractory residue at room temperature $\left(2158 \mathrm{~cm}^{-1}\right)$ could be compatible with the trend of the recorded peak position of the $\mathrm{OCN}^{-}$ion into the ice.

Our experimental results show that the organic residues containing nitrogen, carbon and hydrogen present similar features in the spectral region $2300-2000 \mathrm{~cm}^{-1}$. That is clear looking at Fig. 7, where the spectra of Res \#4 and Res \#5 are magnified six and three times respectively to facilitate the comparison with the spectrum of the residue Res \#1. In particular, both Res \#1 and Res \#5 exhibit the five features stressed by the vertical lines in Fig. 7 and already mentioned. Moreover the two overall structured bands look very similar one another, although Sample \#1 and Sample \#5 had different composition and $\mathrm{N}$ to $\mathrm{C}$ ratio before ion bombardment and they suffered different amount of energy deposited by incoming ions. Even Res \#4 presents the same five components although with slight differences: in fact the overall profile of the band is different and the features at 2192, 2138 and $2103 \mathrm{~cm}^{-1}$ present slight shifts towards lower wavenumbers. Since Res \#4 and Res \#5 come from two icy mixtures with identical molecular composition (albeit with different ratio) and suffer identical dose, the differences observed in the two spectra are certainly attributable to the different values of atomic N/C.

\subsubsection{Spectral region: $1900-1000 \mathrm{~cm}^{-1}$}

The specific assignment of the features in the spectral region $1900-1000 \mathrm{~cm}^{-1}$ is not easy because different functional groups fall in this region often overlapping one another. Looking at Fig. 8, we observe an overlap of features in the spectra of the 


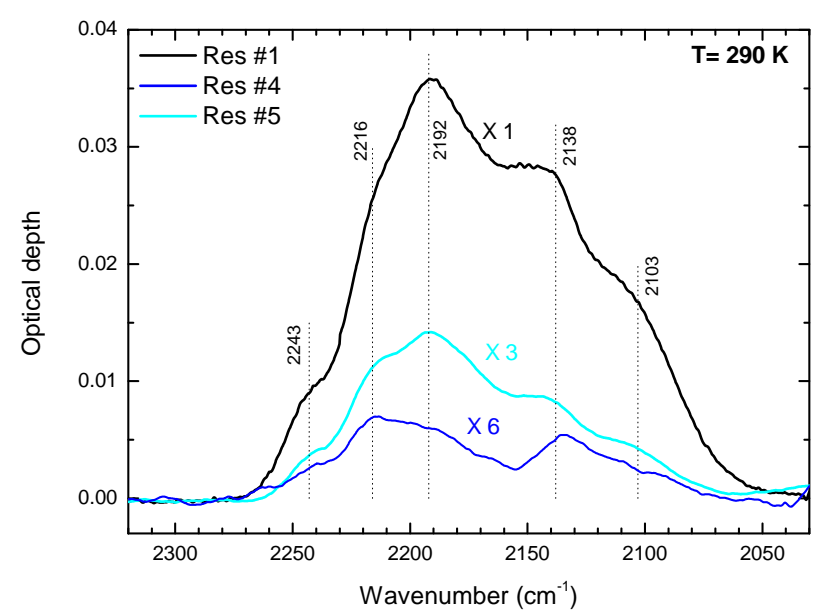

Fig. 7. Infrared spectra (2300-2000 $\mathrm{cm}^{-1}$ region) of Res\#1, Res \#4 and Res \#5. The spectra of Res \#4 and Res \#5 are magnified six and three times respectively for the sake of clarity.

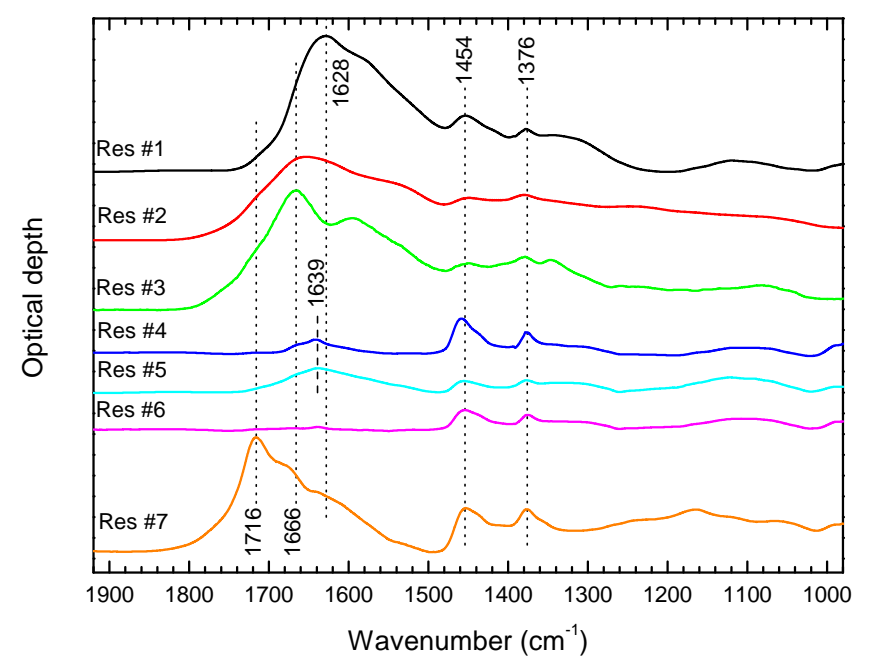

Fig. 8. Infrared spectra $\left(1900-1000 \mathrm{~cm}^{-1}\right.$ region) of the seven organic residues analysed in this work. Spectra are collected in situ at room temperature.

seven residues due to a blend of the features of different functional groups. According to the assignment reported in literature (e.g. Imanaka et al. 2004; Dartois et al. 2013; Materese et al. 2015), carbonyl stretching modes $(\mathrm{C}=\mathrm{O})$ fall at about $1700 \mathrm{~cm}^{-1}$, $\mathrm{sp}^{2} \mathrm{C}=\mathrm{C}$ and $\mathrm{C}=\mathrm{N}$ stretching modes fall between 1650 and $1500 \mathrm{~cm}^{-1}$ and $\mathrm{NH}_{2}$ bending modes at about $1600 \mathrm{~cm}^{-1}$. The presence or the intensity of these features depends on the relative abundances of the elements $\mathrm{N}, \mathrm{C}, \mathrm{O}$, and $\mathrm{H}$ in the initial icy mixtures.

All the seven residues display two features at 1454 and $1376 \mathrm{~cm}^{-1}$ that we can assign to the aliphatic $\mathrm{C}-\mathrm{H}$ bending modes (Quirico et al. 2008). The presence of these two bands is consistent with the detection of the three bands due to C-H stretching bonds and falling respectively at 2960, 2927 and $2870 \mathrm{~cm}^{-1}$ (Fig. 3).

Res \#7 contains $\mathrm{C}, \mathrm{O}$, and $\mathrm{H}$ elements and its spectrum displays a sharp band peaked at $1716 \mathrm{~cm}^{-1}$ due to $\mathrm{C}=\mathrm{O}$ stretching mode probably indicating the presence of aldehydes, ketones and/or carboxylic acids. The $1716 \mathrm{~cm}^{-1}$ feature could also be present in the spectra of Res \#2 and Res \#3 blended in the broad band centred at about $1600 \mathrm{~cm}^{-1}$. Res \#1 contains $\mathrm{N}, \mathrm{C}$, and $\mathrm{H}$ elements and its multi-component broad band between
Table 2. Elemental composition of three organic residues by XPS analysis.

\begin{tabular}{lcccc}
\hline \hline Res \#1 & \multicolumn{5}{c}{ Peak position (eV) } \\
$\mathrm{C}(73.4 \%)$ & 285.0 & 286.5 & 288.1 & - \\
$\mathrm{N}(21.8 \%)$ & 399.6 & - & - & - \\
$\mathrm{O}(3.6 \%)$ & 532.2 & - & - & - \\
\hline Res \#4 & \multicolumn{3}{c}{ Peak position (eV) } \\
$\mathrm{C}(94.0 \%)$ & 285.0 & 286.5 & 288.1 & - \\
$\mathrm{N}(2.4 \%)$ & 399.7 & - & - & - \\
$\mathrm{O}(3.6 \%)$ & 532.6 & - & - & - \\
\hline Res \#3 & \multicolumn{7}{c}{ Peak position $(\mathrm{eV})$} & & \\
$\mathrm{C}(64.5 \%)$ & 285.0 & 286.5 & 288.1 & 289.0 \\
$\mathrm{~N}(18.4 \%)$ & 400.1 & 398.5 & - & - \\
$\mathrm{O}(17.1 \%)$ & 532.6 & 531.5 & - & - \\
\hline
\end{tabular}

1740 and $1480 \mathrm{~cm}^{-1}$ exhibits at least two peaks at about 1630 and $1580 \mathrm{~cm}^{-1}$ due to different functional groups such as $\mathrm{C}=\mathrm{N}$ heteroaromatics, $\mathrm{C}=\mathrm{C}$ aromatics (stretching) and $-\mathrm{NH}_{2}$ (bending). Res \#4, Res \#5, and Res \#6 do not contain oxygen and their spectra do not display intense features in this region: the weak feature at $1639 \mathrm{~cm}^{-1}$ observed in the spectrum of Res \#4 and Res \#5 (see vertical line in Fig. 8) may be due to regular imines (CN double bonds).

\subsection{XPS spectroscopy}

X-ray photoelectron spectroscopy analyses are performed on three organic residues (Res \#1, Res \#3, and Res \#4) with the aim of evaluating the surface elemental composition and the main organic chemical functional groups present in the samples, keeping in mind the elements of the respective icy mixtures. The observed atomic concentrations (\%) are reported in Table 2.

The XPS spectrum of the residue Res \#1 reveals the presence of carbon $(\sim 73.4 \%)$, nitrogen $(\sim 21.8 \%)$ and a small amount of oxygen (less than $4 \%$ ). In the high-resolution spectrum of the $\mathrm{C} 1 \mathrm{~s}$ region (Fig. 9), we can observe the presence of a main band centred at $285.0 \mathrm{eV}$ (blue line), a shoulder positioned at binding energy of $286.5 \mathrm{eV}$ (red line) and a very weak band detected at $288.1 \mathrm{eV}$ (green line). The band at $285.0 \mathrm{eV}$ is compatible with the presence of the $\mathrm{CH}_{x}, \mathrm{C}-\mathrm{C}$ or $\mathrm{C}=\mathrm{C}$ moieties, which is consistent with the detection of the alkyl and unsaturated groups in the FTIR spectra (e.g. the features due to the $\mathrm{C}-\mathrm{H}$ stretching modes in Fig. 2). The $\mathrm{C} 1 \mathrm{~s}$ component located at $286.5 \mathrm{eV}$ can be described as the contribution from carbon and nitrogen species $(\mathrm{C}-\mathrm{N}, \mathrm{C}=\mathrm{N}$ and $\mathrm{C} \equiv \mathrm{N})$ as discussed by Nuevo et al. (2011). The low-intensity band positioned at the highest binding energy, specifically at $288.1 \mathrm{eV}$, is likely due to bonds formed between carbon and oxygen, such as carbonyl groups (e.g. Kaba et al. 2005; Ahmed et al. 2013). The presence of oxygen in Res \#1 is not expected because of the lack of oxygenbearing species in the icy mixture of Sample \#1; nonetheless, the formation of $\mathrm{C}=\mathrm{O}$ species can reasonably occur as the result of the reaction of the surface reactive species with the atmospheric $\mathrm{H}_{2} \mathrm{O}$ and/or $\mathrm{O}_{2}$. The N1s XPS region of Res \#1 shows a band positioned at $399.6 \mathrm{eV}$ with a FWHM of $2.4 \mathrm{eV}$ (Fig. 9). The large width of the band suggests the presence of a variety of nitrogen-containing species. Additionally, the $\mathrm{BE}$ is lower than the typical $\mathrm{BE}$ value found for single $\mathrm{N}-\mathrm{H}, \mathrm{N}-\mathrm{C}$ bonds $(\sim 400.0 \mathrm{eV})$, suggesting that species with electron-rich nitrogen functionalities (e.g. $\mathrm{C}=\mathrm{N} / \mathrm{C} \equiv \mathrm{N}$ ) are present (e.g. Hsu et al. 2010; Matsuoka et al. 2012). This is strongly supported by the 

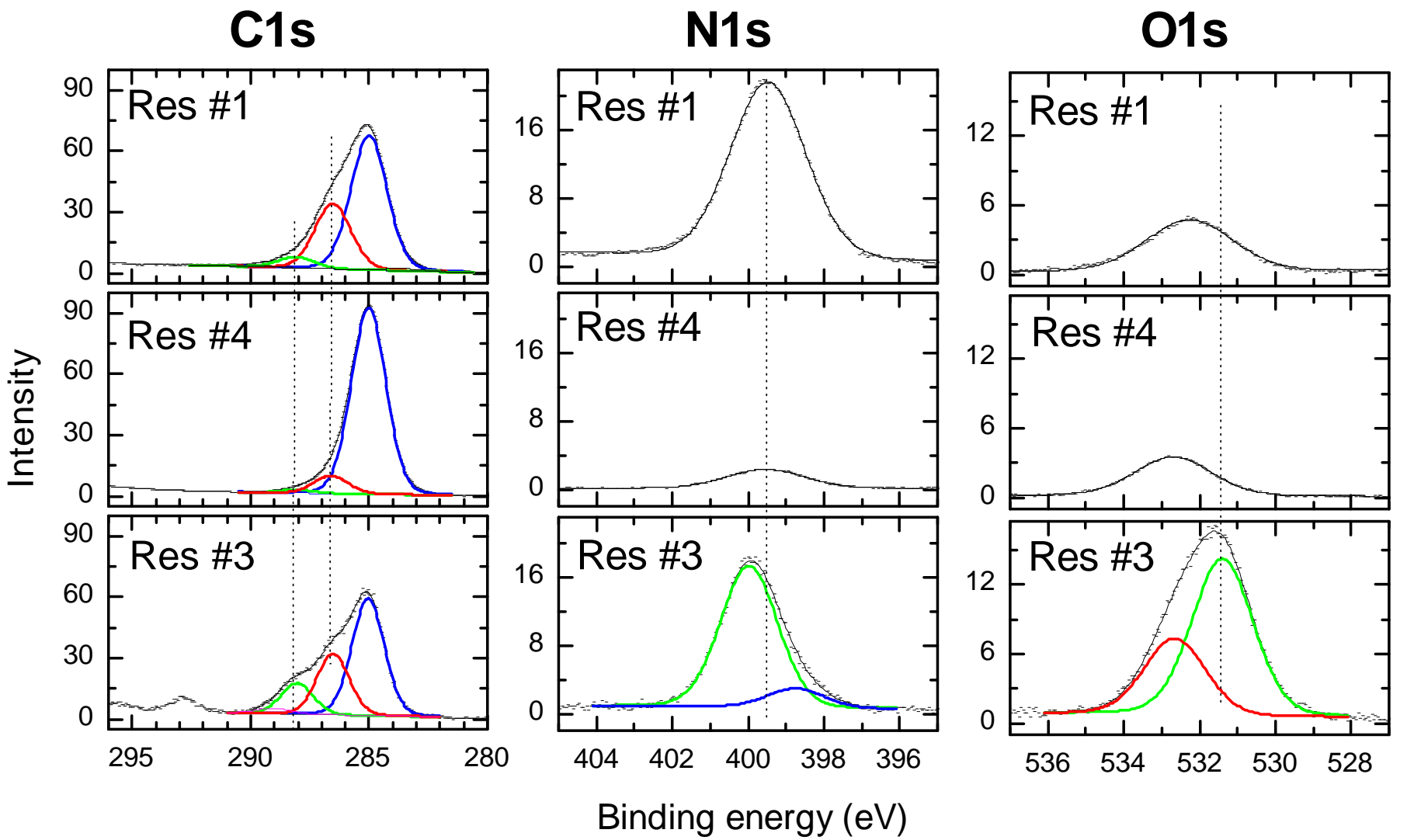

Fig. 9. XPS spectra of Res \#1, Res \#3, and Res \#4 in the C1s, N1s, and O1s spectral regions.

FTIR features showing the presence of imine $\left(\sim 1640 \mathrm{~cm}^{-1}\right)$ and nitrile groups $\left(\sim 2200 \mathrm{~cm}^{-1}\right)$, as well of amines $\left(\sim 3400 \mathrm{~cm}^{-1}\right)$. It is to be noticed, in addition, that there is a good correspondence between the XPS percentage of the band at $286.5 \mathrm{eV}$ in the $\mathrm{C} 1 \mathrm{~s}$ region $(22.5 \%)$ and the atomic percentage of the nitrogen in the sample $(21.8 \%$, see Table 2$)$. The weak signal in the $\mathrm{O} 1 \mathrm{~s}$ region (Fig. 9) consists of a broad band (FWHM $=2.6 \mathrm{eV}$ ) with the maximum positioned at $532.2 \mathrm{eV}$, which is compatible with the presence of different typologies of $\mathrm{C}=\mathrm{O}$ bonds. The presence of the oxygen-containing moieties in the sample is negligible and essentially due to the surface or environment interaction.

The XPS analysis of Res \#4, obtained by ion irradiation of the icy mixture $\mathrm{N}_{2}: \mathrm{C}_{8} \mathrm{H}_{18}(1: 1)$, indicates the presence of carbon $(94.0 \%)$, nitrogen $(2.4 \%)$ and, similarly to the Res \#1, a small amount of oxygen (3.6\%). If compared to Res \#1, the amount of nitrogen is notably reduced by a factor of ten. As results, Res \#4 is mainly constituted of $\mathrm{C}-\mathrm{C} / \mathrm{C}=\mathrm{O}$ and $\mathrm{C}-\mathrm{H}$ containing species. The different compositions observed in the two samples Res \#1 and Res \#4 are roughly ascribable to the following factors: i) the different $\mathrm{C}$ to $\mathrm{N}$ atomic ratio of the two mixtures; and ii) the different reactivity of the two hydrocarbons. Although different concentrations are observed, similar organic functionalities are found in both residues. The $\mathrm{C} 1 \mathrm{~s}$ spectral region of the Res \#4 (Fig. 9) shows the predominant presence of the $\mathrm{C} 1 \mathrm{~s}$ component centred at $285.0 \mathrm{eV}$ due to the $\mathrm{CH}_{x}$, $\mathrm{C}-\mathrm{C}$ and $\mathrm{C}=\mathrm{C}$ moieties, a small band at $286.5 \mathrm{eV}$ and a negligible band at $288.1 \mathrm{eV}$. The predominant presence of $\mathrm{CH}_{x}, \mathrm{C}-\mathrm{C}$ and $\mathrm{C}=\mathrm{C}$ moieties is also supported by FTIR data which show intense modes of the aliphatic $\mathrm{CH}_{x}$ at $2900 \mathrm{~cm}^{-1}$. The component at $286.5 \mathrm{eV}$ is attributed to the presence of the $\mathrm{CN}$ species similarly to the N1s XPS spectrum of the Res \#1. In this case, the contribution at higher $\mathrm{BE}$ values $(288.1 \mathrm{eV})$ associated to the presence of oxidized carbon species is negligible. Despite the lower intensity, the shape and the position of N1s band of the Res \#4 (Fig. 9) are similar to those observed for Res \#1 $(\mathrm{FWHM}=2.4 \mathrm{eV}$ and $\mathrm{BE}=399.7 \mathrm{eV})$, indicating the presence of $\mathrm{C}=\mathrm{N} / \mathrm{C} \equiv \mathrm{N}$. The small amount of nitrogen detected by XPS is in agreement with the low intensity of the FTIR modes at $2200 \mathrm{~cm}^{-1}$ and at $1640 \mathrm{~cm}^{-1}$ associated to $-\mathrm{C} \equiv \mathrm{N} /-\mathrm{N} \equiv \mathrm{C}$ and $\mathrm{C}=\mathrm{N}$ respectively. Finally, the low O1s band (Fig. 9) suggests the presence of oxidized species, due to the interaction of the surface with the environment analogously with Res \#1. Therefore the XPS characterization of Res \#1 and Res \#4 indicates that either methane or octane in presence of $\mathrm{N}_{2}$ in the irradiated icy mixtures leads to the formation of $\mathrm{C}-\mathrm{C}, \mathrm{C}=\mathrm{C}$, and $\mathrm{C}-\mathrm{N}$, $\mathrm{C}=\mathrm{N}$, and $\mathrm{C} \equiv \mathrm{N}$ functionalities. However, different percentages are found due to different lengths of the hydrocarbon chains.

In order to better elucidate the effect of the presence of water in the icy mixture, we analysed Res \#3, the organic residue produced from the proton bombardment of the icy mixture $\mathrm{N}_{2}: \mathrm{CH}_{4}: \mathrm{H}_{2} \mathrm{O}(1: 1: 1)$. The X-ray photoelectron spectroscopy analysis shows the presence of carbon $(\sim 64.5 \%)$, nitrogen $(\sim 18.4 \%)$ and oxygen $(\sim 17.1 \%)$. In this case, the fraction of oxygen is greater compared to Res \#1 and Res \#4 because of the presence of water in the frozen gas mixture before ion irradiation. The high-resolution spectrum of the $\mathrm{C} 1$ s region (Fig. 9) shows a structured signal that can be fitted with three main components picked at 285.0, 286.5, 288.1 and a small contribution at $289.0 \mathrm{eV}$. The latter, which is assigned to the presence of carboxylic acid $(-\mathrm{COOH})$, is not revealed in the spectra of the other two samples Res \#1 and Res \#4 and it is reasonably due to the action of the water in the icy mixture. The contribution relative to the hydrocarbon species lying at $285.0 \mathrm{eV}$ is lower 
compared to the contribution of these species observed in the previous residues in agreement with the lower intensity of the $\mathrm{CH}_{x}$ features (at about $2900 \mathrm{~cm}^{-1}$ ) observed in the FTIR spectra. The band at $286.5 \mathrm{eV}$ is associated to the contributions from $\mathrm{CN}(\mathrm{C}-\mathrm{N}, \mathrm{C}=\mathrm{N}, \mathrm{C} \equiv \mathrm{N})$ groups similarly to the previous residues. In this case some contribution due to $\mathrm{C}-\mathrm{O}$ containing species cannot be excluded. It is of interest to notice that the band at $288.1 \mathrm{eV}$, also present in the XPS spectra of Res \#1 and Res \#4 as result of C-oxidation due to oxygen contamination, is significantly increased in the spectrum of the Res \#3, as expected for the presence of the water in the mixture. We note that in the literature, the position of this band could be associated to the $\mathrm{C}$ of $\mathrm{N}=\mathrm{C}=\mathrm{O}^{-}$ions (Mavis \& Akinc 2006). However the presence of amides $(>\mathrm{N}-\mathrm{C}=\mathrm{O})$ cannot be excluded. The formation of $\mathrm{OCN}^{-}$ or amides could be due to the interaction between water and the organic $\mathrm{C} \equiv \mathrm{N}$ residues (e.g. hydrolysis). In order to better clarify this point, it is important to compare the N1s and O1s spectral features of the samples obtained in presence (Res \#3) and in absence of water (Res \#1 and Res \#4). The N1s signal of Res \#3 appears asymmetric and narrower with respect to the two previous cases, showing a main band positioned at 400.1 and a much smaller contribution at $398.5 \mathrm{eV}$ both with FWHM of $1.8 \mathrm{eV}$. The interpretation of the peak at $400.1 \mathrm{eV}$ is not unambiguous, being compatible with the presence of amine and amides (e.g. Amaral et al. 2005; Ramanathan et al. 2005; Rao et al. 2014). The band at $398.5 \mathrm{eV}$ can be due to the presence of electronrich nitrogen atoms as in the case of aromatic imine (e.g. Yamashige et al. 2005; Kretschmann et al. 2007). We note the lack of the component lying around 399.6-399.7 eV, associated to the nitrile groups (Gammon et al. 2003). This could be related to the abrupt decrease of the intensity of the IR band peaked at $2158 \mathrm{~cm}^{-1}$ over time: in fact, following by IR spectroscopy the natural evolution over time of a organic residue identical to Res \#3, we note that the band peaked at $2158 \mathrm{~cm}^{-1}$ exhibits a gradual reduction in intensity over time, decreasing by $60 \%$ after two weeks and almost by $100 \%$ after 150 days. In addition, the O1s spectrum of Res \#3 presents an asymmetric signal with a main component at $531.5 \mathrm{eV}$ and a shoulder at $532.6 \mathrm{eV}$. The latter is commonly attributed to generic $\mathrm{C}-\mathrm{O} / \mathrm{C}=\mathrm{O}$ bonds, whilst the band at a value as low as $531.5 \mathrm{eV}$ is typically reported for oxygen with a partial negative character as expected for $\mathrm{OCN}^{-}$ or amides (e.g. Clochard et al. 2007; Rück-Braun et al. 2013). Thus XPS data support the spectral findings obtained by the FTIR technique, which show notable differences in the absorption features between $1600-1700 \mathrm{~cm}^{-1}$. Our results indicate that the composition of the organic residue is strongly affected by the presence (or the lack) of $\mathrm{H}_{2} \mathrm{O}$ which induces the formation of $\mathrm{OCN}^{-}$functionalities.

\section{Discussion}

The comparative study of the seven organic residues presented in this work points out the chemical similarities and differences between them. For instance, all the solid samples here analysed display the aliphatic C-H stretching (2960, 2927 and $2870 \mathrm{~cm}^{-1}$ ) and bending (1454 and $1376 \mathrm{~cm}^{-1}$ ) features, namely every icy mixture containing hydrocarbons, if subjected to ion irradiation, produces organic residues having long aliphatic chains. The intensity of these features depends on the relative atomic abundance and on the total amount of energy released by ions on the ice.

If the icy mixture contains nitrogen, as well as hydrogen and carbon (e.g. Sample \#1, Sample \#4, and Sample \#5), the proton bombardment and the following annealing to room temperature produces an organic residue whose infrared spectrum exhibits a structured feature in the region $2300-2000 \mathrm{~cm}^{-1}$ due to nitrile and isonitrile terminal groups. Indeed, we can assert that the three residues, Res \#1, Res \#4, and Res \#5, contain similar functional groups as the same five components of the $2200 \mathrm{~cm}^{-1}$ feature are recognizable for each sample (see Fig. 7). In this paper, Res \#1 is taken as example of organic residue obtained after ion irradiation of an icy mixture containing carbon, hydrogen and nitrogen, but free of oxygen. Looking at the spectrum of Sample \#1 just after proton bombardment at $17 \mathrm{~K}$ and at $120 \mathrm{~K}$ during the warm-up, the features observed in the region $2300-2000 \mathrm{~cm}^{-1}$ are weaker than those observed for Sample \#2 and Sample \#3 (see top and central panel of Fig. 5). However, at room temperature, Res \#1 displays a strong and structured feature in the same spectral region. This demonstrates that additional chemical changes occur at temperatures higher than $120 \mathrm{~K}$ during the warm-up, when molecules and radicals become more mobile and could react each other more readily.

Both Sample \#2 and Sample \#3 contain hydrogen, carbon, nitrogen, and oxygen. However, their corresponding organic residues (Res \#2 and Res \#3) do not display the same functional groups that give rise to the $2200 \mathrm{~cm}^{-1}$ feature. This is evident looking at the infrared spectra of the two samples in the region $2300-2000 \mathrm{~cm}^{-1}$ : both show two multi-peaked bands, but with profiles and components different one another. Thus Res \#2 exhibits a $2200 \mathrm{~cm}^{-1}$ feature comparable to those observed for Res \#1, Res \#4, and Res \#5 (see the bottom panel of Fig. 5), whereas Res \#3 displays a quite sharp feature centred at $2158 \mathrm{~cm}^{-1}$. We think that the presence of water as component of Sample \#3 can affect the chemical rearrangements during proton bombardment at $17 \mathrm{~K}$ and especially during the annealing to room temperature, preventing or reducing the formation of molecules containing nitrile and iso-nitrile groups and encouraging the formation of molecules containing amide groups, as already stressed by commenting the XPS spectra in the previous section. Looking at the IR spectrum of Res \#3, we are not sure about the chemical groups responsible of the band centred at $2158 \mathrm{~cm}^{-1}$, even if we hypothesize a contribution of $\mathrm{OCN}^{-}$still trapped in the organic residue (Res \#3) at room temperature. $\mathrm{OCN}^{-}$ion is one of the new species formed at $17 \mathrm{~K}$ after energetic processing of a frozen icy mixture containing oxygen, carbon and nitrogen bearing species (e.g. van Broekhuizen et al. 2005). Indeed it has been detected both in Sample \#2 and in Sample \#3 after proton bombardment (see the top panel of Fig. 5). During the annealing of Sample \#3, we have recorded the $\mathrm{OCN}^{-}$peak position as a function of the sample temperature: we recognize a gradual shift towards lower wavenumbers as the sample temperature increases, from $2167 \mathrm{~cm}^{-1}$ at $17 \mathrm{~K}-$ $2160 \mathrm{~cm}^{-1}$ at $260 \mathrm{~K}$. Therefore the frequency of the peak observed for the refractory residue at room temperature $\left(2158 \mathrm{~cm}^{-1}\right)$ could be compatible with the trend of the recorded peak position of the $\mathrm{OCN}^{-}$ion into the ice, as shown in Fig. 6.

In this section, we are mainly focusing on the spectral region $2300-2000 \mathrm{~cm}^{-1}$ due to its link with astrobiological studies. In fact the triple $\mathrm{CN}$ bond stretching mode of nitriles considered relevant to pre-biotic chemistry falls in this region. The role of nitriles in formation of various pre-biotic compounds has been illustrated by Matthews \& Minard (2006). Our experimental results demonstrate that the presence of oxygen in the icy samples is not necessary for the formation, at room temperature, of the multi-component band at $2200 \mathrm{~cm}^{-1}$ that we identify with nitrile $(-\mathrm{C} \equiv \mathrm{N})$ and isonitrile $(-\mathrm{N} \equiv \mathrm{C})$ functional groups.

The refractory residues containing nitrogen, such as those analysed in this paper, seem to be good analogues of the 
materials formed in the outermost solar system, in particular on the surface of those objects whose temperature allow the condensation of nitrogen. For instance, some ultra carbonaceous Antarctic micro-meteorites exhibit IR signatures that are similar to those observed in the organic residues analysed in this work (Dartois et al. 2013, 2018). In particular some of these micro-meteorites present the $2200 \mathrm{~cm}^{-1}-\mathrm{C} \equiv \mathrm{N}$ nitrile feature. It is thought that this high organic carbon content ( $>50 \%$ vol.) and high N/C (e.g. 0.12 in DC65) micro-meteorites originated in the outer solar system beyond the nitrogen snow-line, for example in an Oort-cloud comet in billions of years by cosmic ray irradiation (Dartois et al. 2013, 2018).

\section{Conclusion}

The experimental results presented so far point out that ion irradiation of simple ice mixtures containing $\mathrm{C}, \mathrm{N}, \mathrm{O}$, and $\mathrm{H}$ atoms, leads to the formation of organic residues that are stable at room temperature. Infrared and XPS spectroscopies have shown that the organic residues exhibit a high chemical complexity pointed out by the presence of different functional groups such as amines, amides and nitriles. Further analysis using other techniques (such as gas chromatography and mass spectroscopy) would give additional information on the complex organic content of the solid samples discussed in this paper.

Material similar to that synthesized in laboratory could have been produced on the surfaces of solar system objects beyond the nitrogen snow-line, such as comets in the Oort cloud, by galactic cosmic-ray irradiation. When a comet enters in the inner solar system and the coma develops, a large quantity of dust is lost. This dust constitutes a significant fraction of the IDPs that reach the Earth atmosphere. Hence organic material analogue to that we synthesized in laboratory could have reached the early Earth. One of the key points for the synthesis of the first biomonomers, is the availability of suitable precursor organics in primitive Earth conditions (Ruiz-Mirazo et al. 2014). It has been estimated that the delivery of organic carbon (mostly by IDPs, comets and meteorites) on the early Earth was of the order of $10^{8} \mathrm{~kg} \mathrm{yr}^{-1}$, or $10^{16} \mathrm{~kg}$ per 100 million years (Chyba \& Sagan 1992). Since there is about $6 \times 10^{14} \mathrm{~kg}$ of organic matter in the present biosphere, it is likely that the role of extraterrestrial organics was significant (Ruiz-Mirazo et al. 2014). Among the organics that could have had a role in providing the bricks from which life could be initiated, there are the nitriles. Indeed nitriles could be key intermediates in forming amino acids thus providing one of the basic ingredients for life (e.g. Kaiser \& Balucani 2001; Matthews \& Minard 2006).

Acknowledgements. This research has been supported by the Italian Space Agency (ASI) contract no.2013-073-R.0: PSS (Photochemistry on the Space Station). G.F. is funded by the European Union's Horizon 2020 research and innovation programme under the Marie Sklodowska-Curie grant agreement No. 664931 .

\section{References}

Ahmed, M. H., Byrne, J. A., McLaughlin, J., \& Ahmed, W. 2013, JBN, 4, 194 Altwegg, K., Balsiger, H., Bar-Nun, A., et al. 2016, Sci. Adv., 2, 5

Amaral, I. F., Granja, P. L., \& Barbosa, M. A. 2005, J. Biomater Sci. Polym. Ed., 16,1575

Baratta, G. A., Chaput, D., Cottin, H., et al. 2015, Planet Space Sci., 118, 211

Bennett, C. J., Jones, B., Knox, E., et al. 2010, ApJ, 723, 641

Brunetto, R., Barucci, M. A., Dotto, E., \& Strazzulla, G. 2006, ApJ, 644, 646

Chyba, C., \& Sagan, C. 1992, Nature, 355, 125

Clochard, M., Cuscito, O., Berthelot, T., et al. 2007, React (Polym: Funct). 77
Cobb, A. K., Pudritz, R. E., \& Pearce, B. K. D. 2015, ApJ, 809, 6 Dartois, E., Engrand, C., Brunetto, R., et al. 2013, Icarus, 224, 243 Dartois, E., Engrand, C., Duprat, J., et al. 2018, A\&A, 609, A65

d'Hendecourt, L. B., Allamandola, L. J., Grim, R. J. A., \& Greenberg, J. M. 1986, A\&A, 158, 119

Fedo, C. M., Whitehouse, M. J., Kamber, B.S., et al. 2006, Phil. Trans. R. Soc. London Ser. B, 361, 851

Fedoseev, G., Ioppolo, S., Zhao, D., Lamberts, T., \& Linnartzet, H. 2015, MNRAS, 446, 439

Ferini, G., Baratta, G. A., \& Palumbo, M. E. 2004, A\&A, 414, 757

Gammon, W. J., Kraft, O., Reilly, A. C., \& Holloway, B. C. 2003, Carbon, 41, 1917

Gautier, T., Carrasco, N., Mahjoub, A., et al. 2012, Icarus, 221, 320

Greenberg, J. M., Yencha, A. J., Corbett, J. W., \& Frisch, H. L. 1972, Mem. Soc. R. Sci. Liege, $425,6^{e}$ serie, tome III

Greenberg, J. M., Li, A., Mendoza-Gómez, C. X., et al. 1995, ApJ, 455, L177

Hsu, C. H., Wu, H. M., \& Kuo, P. L. 2010, Chem. Commun., 46, 7628

Hudson, R. L., Moore, M. H., \& Gerakines, P. A. 2001, ApJ, 550, 1140

Hudson, R. L., Moore, M. H., Dworkin, J. P., Martin, M. P., \& Pozun, Z. D. 2008, Astrobiology, 8, 771

Imanaka, H., Khare, B. N., Elsila, J. E., et al. 2004, Icarus, 168, 344

Islam, F., Baratta, G. A., \& Palumbo, M. E. 2014, A\&A, 561, A73

Kaba, M., Raklaoui, N., Guimon, M. F., \& Mas, A. 2005, J. Appl. Polym. Sci., 97, 2088

Kaiser, R. I., \& Balucani, N. 2001, Acc. Chem. Res., 34, 699

Kretschmann, A., Walz, M. M., Flechtner, K., Steinrücka, H. P., \& Gottfried, J. M. 2007, Chem. Commun., 568,

Materese, C. K., Cruikshank, D. P., Sandford, S. A., et al. 2014, ApJ, 788, 111

Materese, C. K., Cruikshank, D. P., Sandford, S. A., Imanaka, H., \& Nuevo, M. 2015, ApJ, 812, 150

Matsuoka, M., Isotani, S., Mansano, R. D., et al. 2012, WJNSE, 2012, 92

Matthews, C. N., \& Minard, R. D. 2006, FaDi, 133, 393

Mavis, B., \& Akinc, M. 2006, Chem. Mater., 18, 5317

Moore, M. H., Hudson, R. L., \& Gerakines, P. A. 2001, Spectrochim. Acta A, 57,843

Muñoz Caro, G. M., Meierhenrich, U. J., Schutte, W. A., et al. 2002, Nature, 416, 403

Muñoz Caro, G. M., Dartois, E., Boduch, P., et al. 2014, A\&A, 566, A93

Mutsukura, N., \& Akita, K. 1999, Thin Solid Films, 349, 115

Novozamsky, J. H., Schutte, W. A., \& Keane, J. V. 2001, A\&A, 379, 588

Nuevo, M., Bredehöft, J. H., Meierhenrich, U. J., d'Hendecourt, L., \& Thiemann, W. H. P. 2010, AsBio, 10, 245

Nuevo, M., Milam, S. N., Sandford, S. A., et al. 2011, AdSpR, 48, 1126

Öberg, K. I., Garrod, R. T., van Dishoeck, E. F., \& Linnartz, H. 2009, A\&A, 504, 891

Palumbo, M. E., Strazzulla, G., Pendleton, Y. J., \& Tielens, A. G. G. M. 2000a, ApJ, 534, 801

Palumbo, M. E., Pendleton, Y. J., \& Strazzulla, G. 2000b, ApJ, 542, 890

Palumbo, M. E., Ferini, G., \& Baratta, G. A. 2004, AdSpR, 33, 49

Pendleton, Y. J., Tielens, A. G. G. M., Tokunaga, A. T., \& Bernstein, M. P. 1999, ApJ, 513, 294

Pontoppidan, K. M., Fraser, H. J., Dartois, E., et al. 2003, A\&A, 408, 981

Quirico, E., Montagnac, G., Lees, V., et al. 2008, Icarus, 198, 218

Ramanathan, T., Fisher, F. T., Ruoff, R. S., \& Brinson, L. C. 2005, Chem. Mater. 17,1290

Rao, K. S., Senthilnathan, J., Ting, J. M., \& Yoshimura, M. 2014, Nanoscale, 2014, 12758

Rothard, H., Domaracka, A., Boduch, P., et al. 2017, J. Phys. B At., Mol. Opt. Phys., 50, 062011

Ruiz-Mirazo, K., Briones, C., \& de la Escosura, A. 2014, Chem. Rev., 114, 285 Rück-Braun, K., Petersen, M. A., Michalik, F., et al. 2013, Langmuir, 29, 11758

Strazzulla, G., Baratta, G. A., \& Palumbo, M. E. 2001, Spectrochim. Acta A, 57, 825

Strazzulla, G., \& Johnson, R. E. 1991, Comets in the post-Halley Era, 1, ASSL Series, Dordrecht, 243

Urso, R. G., Scirè, C., Baratta, G. A., Compagnini, G., \& Palumbo, M. E. 2016, A\&A, 594, A80

Urso, R. G., Scirè, C., Baratta, G. A., et al. 2017, PCCP, 19, 32

van Broekhuizen, F. A., Pontoppidan, K. M., Fraser, H. J., \& van Dishoeck, E. F. 2005, A\&A, 441, 249

Yamashige, H., Matsuo, S., Kurisaki, T., \& Wakita, H. 2005, Anal. Sci., 21, 634

Ziegler, J. F., Biersack, J. P., \& Ziegler, M. D. 2008, The Stopping and Range of Ions in Solids (New York: Pergamon Press), 321 